University of Nebraska - Lincoln

DigitalCommons@University of Nebraska - Lincoln

Educational Psychology Papers and

Publications

Educational Psychology, Department of

September 1996

\title{
Site-Based Transdisciplinary Educational Partnerships: \\ Development, Implementation, and Outcomes of a Collaborative Professional Preparation Program
}

\author{
Marshall Welch \\ University of Utah, mwelch@sa.utah.edu \\ Susan M. Sheridan \\ University of Nebraska-Lincoln, ssheridan2@unl.edu \\ Brett Wilson \\ University of Utah \\ Denise Colton \\ University of Utah \\ John C. Mayhew \\ University of Utah
}

Follow this and additional works at: https://digitalcommons.unl.edu/edpsychpapers

Part of the Educational Psychology Commons

Welch, Marshall; Sheridan, Susan M.; Wilson, Brett; Colton, Denise; and Mayhew, John C., "Site-Based Transdisciplinary Educational Partnerships: Development, Implementation, and Outcomes of a Collaborative Professional Preparation Program" (1996). Educational Psychology Papers and Publications. 7.

https://digitalcommons.unl.edu/edpsychpapers/7

This Article is brought to you for free and open access by the Educational Psychology, Department of at DigitalCommons@University of Nebraska - Lincoln. It has been accepted for inclusion in Educational Psychology Papers and Publications by an authorized administrator of DigitalCommons@University of Nebraska - Lincoln. 


\title{
Site-Based Transdisciplinary Educational Partnerships: Development, Implementation, and Outcomes of a Collaborative Professional Preparation Program
}

\author{
Marshall Welch, Susan M. Sheridan, Brett \\ Wilson, Denise Colton, and John C. Mayhew \\ University of Utah
}

In this article, we describe the conceptual framework, development, implementation, and outcomes of an experimental professional preparation program. University students from preparation programs in general education, educational administration, school psychology, and special education formed transdisciplinary cohorts that were placed in school settings to complete a variety of activities designed to foster greater collaboration among disciplines in serving children and youth at risk. We describe what was learned throughout the project as well as its operational structure, outcomes, and future directions for transdisciplinary professional development.

Collaboration among disciplines within education is useful for promoting a common language, knowledge base, and an understanding of the diverse and complex functions of schools and schooling. Familiarity with roles, responsibilities, and techniques among related professions enhances delivery of services through educational partnerships (Blaine \& Sobsy, 1983; Golightly, 1987). In theory and practice, collaborative efforts result in positive professional interdependence in order to achieve a common, agreed-upon goal (Villa \& Thousand, 1988). An 
important question that has not been adequately addressed is how are prospective educators prepared to work collaboratively in meeting the needs of students at risk?

A major barrier to the establishment of collaboration in the schools is the isolated preservice preparation of professionals (Goodlad \& Field, 1993; Kaufman \& Hallahan, 1993; Pugach \& Allen-Meares, 1985; Sindelar, Pugach, Griffen, \& Seidl, 1995; Welch \& Sheridan, 1993). To overcome this barrier, universities must be cognizant of similarities and relationships among disciplines and provide coursework and applied experiences for prospective professionals that will facilitate collaboration (Golightly, 1987; Sindelar et al., 1995; Strawderman \& Lindsey, 1995).

The Site-Based Transdisciplinary Educational Partnerships Project (STEP) was a 3-year, federally funded project of the Graduate School of Education at the University of Utah. It was designed to address the critical issues enumerated earlier. In this article, we describe the conceptual framework of the STEP project and the use of action research as a tool for professional inquiry. The development, implementation, and outcomes of the project are also reported, followed by a discussion of the challenges encountered and future directions. More important, the discussion of challenges includes candid anecdotal information depicting the "good, bad, and the ugly" that can be considered by other institutions attempting to implement similar programs.

\section{THE STEP PROJECT}

The STEP project was initiated in September 1991 by the Department of Special Education in collaboration with other educational departments (i.e., Educational Administration, Educational Psychology, and Educational Studies; Welch \& Sheridan, 1993). Students from each department fulfilled part of their respective field practica and/or internship requirements in a cooperating public school setting as part of the project's activities. Over the course of the 3-year project, 72 university students from various professional preparation programs (see Table 1) were placed in participating school sites in four school districts surrounding the Salt Lake City area. University students worked in teams with their counterparts from other disciplines in the school to form educational partnerships to meet the needs of students at risk. The collaborative interactions between disciplines in the STEP project reflect what Amedore and Knoff (1993) referred to as boundary spanning that allowed prospective professionals the opportunity to learn more about other disciplines through direct interaction. 
TABLE 1

Number of Student Participants by Discipline for Year 1, 2, and 3

\begin{tabular}{lccr}
\hline & Year I & Year 2 & Year 3 \\
\hline Special education & 9 & 12 & 9 \\
Educational studies & $5^{\mathrm{a}}$ & 13 & $\mathbf{1 4}$ \\
Educational administration & 3 & 2 & 0 \\
Educational psychology & 1 & 4 & 0 \\
Total participants & 18 & 31 & 23 \\
\hline
\end{tabular}

aSecondary education majors only.

\section{Conceptual Framework}

The conceptual framework of the STEP project was an ecological problem-solving model (Welch \& Sheridan, 1995) designed to promote collaboration while serving students at risk and with special needs. Within the context of the project, collaboration has been defined as "a dynamic framework for educational efforts which endorses collegial, interdependent, and co-equal styles of interaction between at least two partners working jointly together to achieve common goals in a decision making process that is influenced by cultural and systemic factors" (Welch \& Sheridan, 1995, p. 11). This ecological focus served as an overarching umbrella under which transdisciplinary teams explored a specific area of need identified at their school site. There was, however, no specific curriculum for the project participants to assimilate or master. Instead, a frame of reference was utilized to allow each individual and the cohort team as a whole the opportunity to consider how educational partnerships empower educators. This frame of reference was based on a paradigm shift that promotes a collaborative ethic (V. Phillips \& McCullough, 1990), whereby educators believe that joint ownership of problems and problem solving will ultimately benefit not only students but other educators and the school as well. The collaborative ethic is realized through an ecological perspective to identify and use a variety of human, technological, informational, physical, and financial resources (Maher \& Bennett, 1984; Welch \& Sheridan, 1995) for collaborative problem solving. Through observations and interviews at project sites, university students identified a specific area of schoolbased need to serve as the focus for an action research project. Resources within the school were employed during action research activities to forge educational partnerships in addressing the identified need. For example, one team of students identified the need to provide an after-school study session to teach learning strategies. The identified area of need provided a context in which students incorporated the ecological resources within the school for action research activities. 


\section{Collaborative Action Research}

Under the overarching focus and frame of reference briefly described previously, the STEP project employed collaborative action research as a vehicle for professional development and inquiry. Collaborative action research "is characterized by its group orientation, focus on practical problems of individual teachers or schools, emphasis on professional development, and construction of an environment that provides time and support for teachers and university staff to work together" (Clift, Veal, Johnson, \& Holland, 1990, p. 53).

This form of research methodology has a long history (Wallace, 1987) and has been effectively used in teacher education programs and staff development (Liston \& Zeichner, 1990; Oja \& Pine, 1987; Ross, 1987). Recently, action research has been used to help educators develop their own skills in working with students at risk (Gove \& Kennedy-Calloway, 1992). This research can take many forms and may be "intentionally idiosyncratic, personalized, and contextual . . . [as] questions for study emerge from needs which are unique to individuals in particular settings" (Kyle \& Hovda, 1987, p. 171). This process allows preprofessionals to apply theory meaningfully (Kosmidou \& Usher, 1991). It has the potential to resolve "the dilemma between formal ivory tower research and the issues of day-to-day practice" (Dowhower, Melvin, \& Sizemore, 1990, p. 23), which serves as a powerful learning tool in professional preparation programs. Project activities were characterized in three domains: inquiry, reflection, and outcomes.

Inquiry. Each individual student and transdisciplinary team sought information and experiences to answer specific professional questions directly related to serving students at-risk and with special needs. During the first 10-week quarter of field experiences, students interacted with their professional counterparts in the field site through interviews, observations, and other activities that are described in detail later. The interaction allowed preprofessionals the opportunity to identify areas of need within the school that might serve as targeted goals for action research. University students attended seminars (described later) every 2 weeks on the university campus. As part of the seminar discussions, individuals and the team as a whole identified a question to be pursued throughout the site-based experience. This inquiry, rather than a predetermined set of curricular objectives, drove the knowledge base and scholarly endeavors of each student and team. Students were expected to apply information from university courses by developing and implementing a school-based project. 
Reflection. As university students completed their inquiry during the field experiences, each was required to reflect upon the needs of students at risk; their personal professional growth; and the ecological framework of resources available within the school and from other disciplines that could be used to impact students in the school, university students, and the school. The reflection process involved maintaining journals and engaging in dialogue during seminar discussions. The journal entries were not merely a running account of events and experiences. Preprofessionals were required to synthesize concepts, such as assumptions and components of the collaborative ethic, and relate the theoretical information to their actual experience in the school settings.

Outcomes. Finally, individual students and teams were expected to quantitatively and qualitatively measure the outcomes of educational partnership projects at three levels: student level, university student level, and school level. The outcome component of the project provided a balance to the inquiry and reflection activities.

\section{PROJECT DEVELOPMENT}

The project was coordinated by the principal investigator, project director, and graduate research assistant. The principal investigator is a tenure-track faculty member who is also coordinator of the teacher education program in the area of mild-to-moderate disabilities. The project director is a clinical faculty member who is responsible for supervising field experiences in the teacher education program in the area of mild-to-moderate disabilities. The project coordinators initially contacted program coordinators from each department within the Graduate School of Education in late 1990 to discuss the conceptual design of the project. There was enormous interest and philosophical support of the project as it was conceptualized. However, the project was immediately beset with an array of challenges once the federal funding was awarded. For example, project coordinators were notified in mid-September 1991 that the project had been approved and that the funding period had actually begun at the beginning of the month. This event left project coordinators scrambling to put components of the project into place well after the academic year had begun. Participating project sites had not yet been identified. Many university students had already been placed in their respective field experience sites. Conse- 
quently, site identification and student recruitment had to take place during the fall quarter in hopes to implement the project by winter and spring quarters.

\section{Logistical and Political Issues}

Philosophical support soon gave way to the hard realities of logistical coordination and political issues. It was quickly discovered that each professional preparation program operated field experiences in very different ways. The Department of Educational Psychology, which prepares school psychologists, incorporated both practica and internships, each with their own demands and time lines that had to adhere to guidelines and stipulations mandated by the American Psychological Association. All of the students from this department were working toward certification as a school psychologist, and most toward master's or doctorate degrees. Consequently, all of the students from the Department of Educational Psychology had some practical experience in school settings either as teachers or practicing school psychologists.

Meanwhile, the Department of Special Education employed three prestudent teaching field experiences for three consecutive academic quarters. Each field experience focused on specific skill areas including assessment, instruction, and behavior management as part of a $\mathrm{K}-12$ postbaccalaureate teacher certification program. All of the students from the Department of Special Education had a bachelor's degree but most had no teaching experience.

Teacher candidates from the Department of Educational Studies (general education) were undergraduates with no prior teaching experience who completed a full-year student teaching experience in a professional development site (PDS) as part of their 5-year preparation program. Preprofessionals in the elementary education program were required to complete a Special Education course entitled "Educational Partnerships" with students from the Department of Special Education. For a detailed description of that course, readers are referred to Welch and Sheridan (1993). However, students in the secondary education program were not required to take coursework in special education. This situation created a discrepancy in teacher candidates' foundation of basic knowledge, which required some retroactive instruction during seminar sessions. For example, it was discovered that teacher candidates from the secondary education program were completely unfamiliar with individualized education programs.

All of the students from Educational Administration were employed as full-time teachers and were earning either a certificate for school administration or an educational doctorate degree. They completed part 
of their field components in their own school prior to taking a full year's leave of absence to complete an internship in a specific school site approved and selected by the program. None of the prospective project sites had previously served as internship sites for the Educational Administration program. Consequently, participation of the administrative interns required securing some release time from their place of employment to complete activities at project sites. Project funds were available to pay for substitute teachers that allowed the students in the administration program the opportunity to spend several afternoons in project sites. One district, however, did not permit the two teachers in the program any release time despite the availability of funds for substitute teachers. Negotiation was thwarted as the district indicated that the release time was against policy and that such a practice would set unwanted precedent. This decision limited the number of participants from the Educational Administration program to 3 during the 1st year of the project. Consequently, project coordinators recruited candidates from the administration program who were not employed in that specific district during the 2nd year of the project. Later, in the 3rd and final year, administration candidates had independently arranged their internship locations, none of which were part of the STEP project. Therefore, no administrative interns were involved in the final year of the STEP project.

As evident from the foregoing description, a daunting challenge facing project coordinators was integrating and coordinating diverse field components and levels of student background to accommodate various programs without compromising the integrity of the respective programs and the project's design. Consequently, project coordinators had to negotiate exceptions to various policies and procedures with each program coordinator. Considerable flexibility and creativity were required and, for the most part, employed. The degree of flexibility is attributed to at least two factors. First, cooperating program coordinators philosophically agreed with the overall scope and purpose of the STEP project. Second, the existing relationships between project and program coordinators was collegial on a personal and professional level.

\section{Resistance}

As with most educational programs requiring some degree of systemic change, resistance was encountered along the way. The greatest deal of resistance appeared to come from certain elementary education faculty. Despite philosophical support from program administrators, the entire clinical faculty responsible for teaching methods courses and supervising teacher candidates' field experiences in one program were less 
receptive to the project. In a large group meeting with the project coordinators, the clinical faculty questioned the need for transdisciplinary field experiences. Many stated they did not understand why classroom teachers needed to have transdisciplinary experiences at the preservice level. A few faculty members felt their teacher candidates already had too many expectations and would be overwhelmed with project activities. Some supervisors expressed concern about an influx of university students from other programs overwhelming the school site. At times, this concern was characterized as a "turf" issue. For example, some clinical faculty referred to "their" PDS and felt it would be compromised in some way by "sharing" it. As potential schools in nearby settings were considered, the clinical faculty indicated that supervising a separate, pilot group of six to seven students in another site would be too inconvenient without some kind of release from their other responsibilities even though there would not be any additional teacher candidates to supervise.

When the dialogued turned to the possibility of identifying alternative field sites, logistical concerns soon combined with philosophical issues. Some of the schools being considered were known to use highly structured instructional and behavioral interventions such as direct instruction and applied behavior analysis and thus were considered unacceptable settings for their teacher candidates. One clinical faculty member requested to see a syllabus of the project seminar to "see if it conflicted" with what she taught in her methods class. Project coordinators attempted to assure the clinical faculty that their students would not be expected to implement any pedagogical approach that was contrary to the program's philosophical or theoretical foundations. Instead, teacher candidates would merely have the opportunity to see other types of programs firsthand. Because of these issues, the teacher education program at the elementary level opted not to participate in the first year of the project. Meanwhile, teacher candidates in the secondary education program were urged by their clinical supervisors to participate in the STEP project as this would be their only exposure to students with special needs.

The elementary education program did eventually participate in the STEP project for its final 2 years. It is, however, unclear as to what led to this change in position. Nevertheless, during subsequent dialogue, clinical faculty from the elementary education program insisted that their existing field sites be used as project sites if their teacher candidates were to participate.

\section{Project Site Identification Process}

The project coordinators met with each university program coordinator to identify schools that had a history of educational partnerships in 
serving students with various needs to serve as project sites. In essence, the project coordinators wanted a pool of possible school sites that were acceptable to each of the preparation programs within the Graduate School of Education. As alluded to earlier, this process was a daunting challenge. For example, one school would be suggested by one program because it was effectively emulating best practices espoused by its discipline only to be rejected by another program because it did not reflect its philosophical or theoretical principles.

The initial intent was to use schools that were already implementing innovative educational partnerships to help instill the collaborative ethic at the preservice level. A list of approximately 10 potential sites from five school districts was eventually generated after considerable discussion. One a pragmatic level, two schools already serving as a PDS for the elementary education program were included as project sites for the 2 nd and 3rd years of the project. A previously indicated, the elementary education program agreed to participate in the project if existing schools were incorporated. These schools were used despite the fact that project coordinators and other program coordinators had not readily identified any existing forms of collaboration in the school that would serve as a model to participating university students. These schools were included as a means of recruiting teacher candidates from the elementary education program.

At the beginning of the project's 1st year, representatives from each of the five school districts were invited to a brunch meeting at the university to describe the project as well as to solicit support and participation. Representatives from three of the five districts attended the meeting. A few schools on the list of prospective sites were thus eliminated from consideration by virtue of the fact their district representatives did not attend the meeting. It should be noted, however, that one of these two districts eventually participated in the final year of the project. The modified list of remaining potential sites was presented and discussed. Project coordinators facilitated the discussion by carefully ensuring that each district representative participated in the discussion. An operational criteria for site identification was used. Potential school sites had to have innovative models of collaboration (e.g., team teaching, collaborative consultation, teacher assistance teams) in place. Other schools were suggested by district administrators but were ultimately eliminated because they had not been included in the initial list of potential sites approved by university program coordinators. A list of six schools was eventually developed. District administrators indicated that the decision to participate was ultimately up to the schools.

Once the list of six schools was generated, the project coordinators presented an overview of the project to the administration, faculty, and staff of each school. Two schools decided not to participate leaving a total 
of two elementary, one middle school, and one senior high schools as participating school sites for the 1st year of the project. The elementary schools were used for the 1st year despite not having any teacher candidates from the elementary education program. University students from the areas of educational administration, school psychology, and special education comprised a transdisciplinary cohort in those settings. Over the course of the 3-year project, a total of four elementary schools, two middle schools, and one senior high school participated as project sites.

\section{Student Recruitment}

Coordinators from respective programs in the Graduate School of Education allowed project coordinators an opportunity to describe the project to university students during on-campus courses. A brief 10-min presentation outlining the project objectives was coupled with a twopage written description. Students were told this would be a unique opportunity to apply theoretically based approaches learned during coursework in authentic tasks and settings. The federal grant provided a modest tuition stipend to students as an incentive to participate. Interested students were asked to complete a data form that collected various demographic information. These students were contacted and asked to attend a second meeting that provided more in-depth information regarding the project. At the end of the meeting, interested university students were asked to sign a commitment form to voluntarily participate in the project. It should be noted there were no university students from the Departments of Educational Psychology and Educational Administration during the 3rd and final year of the project. This unfortunate and unexpected turn of events was due to the fact that students in these programs had already begun their internships at sites other than the STEP project schools and could not be released or relocated. This reflected the classic scenario of details "falling through the cracks" as project coordinators did not begin the recruiting process soon enough. Further complicating factors were that most of the candidates from Educational Administration were completing their internship in the district that would not allow release time to participate in the project. Consequently, the last year of the project was essentially a joint teacher-education project involving teacher candidates from special and general education.

\section{IMPLEMENTATION}

Once university students were recruited, the project director worked with respective university program coordinators to place the trans- 
disciplinary teams in identified school settings. An orientation meeting was held at the university. An overview of the project was reviewed, coupled with a question-and-answer session to clarify any aspects of the project. Participating university students were introduced to each other as they were grouped into their transdisciplinary teams. Transdisciplinary teams spent two consecutive 10 -week quarters in the project site to complete various field experience assignments from their respective programs while attending weekly seminars at the university.

The 2nd year of the project was the most efficient and successful in terms of meeting the project's objectives. Most of the logistical challenges and operational "bugs" had been worked out during the 1st year of the project. Adequate preparation time allowed for site identification and student recruitment. Consequently, each educational discipline was represented in four of the five teams in the 2nd year of the project. Similarly, the field experiences and the nature of the action research activities were better defined and actualized.

\section{Transdisciplinary Field Experiences}

In addition to completing assignments and activities from their respective programs, STEP project participants had to complete a variety of additional interviews, observations, and activities. A generic list of options was provided to the university students who then chose which exercises to complete over the course of their two-quarter field experience (see Table 2). University students had to complete at least one interview with a professional from another discipline in the field site. The general theme of the interview was the importance, process,

TABLE 2

Project Interviews, Observations, and Activities

Conduct an ecological assessment of a classroom

Observe a teacher assistance team

Observe a multidisciplinary team meeting

Observe peer-mediated intervention (peer tutoring, cooperative learning)

Participate in planning/implementing a team-teaching activity

Participate in some activity with a related field (school psychology, social work)

Collaborate in modifying instruction/curriculum

Assess school climate/culture of collaborative ethic

Conduct a systems analysis to develop action plan

Participate in peer-mediated activity (peer tutoring, cooperative learning)

Interview: school administrator, school psychologist, special educator, classroom teacher

Observe a structured recess program (playground social skills)

Observe implementation of learning strategies in school settings 
benefits, and challenges of collaboration in school settings. For instance, teacher candidates from special education discussed cultural variables such as teacher autonomy and attitudes regarding the inclusion of students with disabilities during an interview with the building principal in one school. One example of the observation option was "sitting in" on a multidisciplinary student support team meeting. An illustration of project activities is team teaching. An intern from school psychology worked with general and special education teacher candidates in teaching social skills to students in a general education classroom. Another team-teaching experience included teacher candidates from general and special education working together in a mainstream classroom. The general education teacher taught specific content while the special education teacher modeled the use of various learning strategies for note taking or essay writing.

University students recorded their experiences in journals. These experiences were discussed during seminars. For example, members of one team wrote about their experience with the building principal at one of the school sites. The administrator met individually with each team member to discuss the culture of the school associated with the benefits and barriers to collaboration. Preprofessionals were very candid and reflective about this experience in their journal entry.

\section{Seminars}

Weekly, 2-hr seminars were conducted for two consecutive 10-week quarters. The seminar during the first quarter was designed to present a variety of information that could be used in transdisciplinary educational partnerships. Some of the information was theoretically based. For example, one session was devoted to discussing the components and assumptions of the collaborative ethic (Phillips \& McCullough, 1990). Other sessions were practically oriented with a focus on applying specific skills such as following the steps of an ecological problemsolving approach (Welch \& Sheridan, 1995). Seminar sessions also included guest presentations by educators currently involved in various forms of collaborative partnerships. A panel of special and general education teachers described how they developed and implemented team teaching in a classroom setting where students with mild disabilities were integrated. As mentioned previously, university students also had the opportunity to discuss their interviews, observations, and activities, which led to the generation of ideas for potential action research projects. For example, the transdisciplinary team at the senior high school had observed and learned from interviews that the faculty were concerned about the progress of students who were academically 
at risk but ineligible for special education services. Thus, the inquiry and reflection process of the university students was focused on meeting the needs of students who typically "fall through the cracks." As the first seminar drew to a close, each team was required to identify a topic for action research and develop an action plan to be implemented during the subsequent quarter of field experience.

The major component of the second seminar during the subsequent academic quarter was allocation of time for team members to discuss and coordinate plans for their action research projects in their respective field sites. Each action plan included an evaluation component to assess the effectiveness of the program. It is important to note that the projects were neither designed as nor intended to serve as carefully controlled experimental studies. Instead, the action research projects served as a vehicle for university students to apply newly assimilated skills in learning more about collaboration for serving the needs of students in authentic settings. Because this was a relatively new procedure in the 1st year, the action projects year were not as carefully conceptualized or operationalized as projects were in the final 2 years. Consequently, the action projects during the 1st year of the project were essentially informal observations and activities. However, many of the teams were actively involved in creating innovative projects. For example, one team in an elementary setting developed an entire curriculum for teaching social skills and conflict management strategies using a basketball theme and terminology that was team taught in mainstream classrooms. There was, however, no evaluation component in the project. Consequently, a description of the action projects for the 1st year were not included in the discussion of results presented next. The range of action research projects and their outcomes for Years 2 and 3 are presented in Table 3. A comprehensive, illustrative description of outcomes from one action research project is provided as follows.

\section{OUTCOMES}

There were four sets of outcomes for the STEP project. The most significant outcome was that 72 preprofessionals successfully completed their respective programs within the context of the STEP project. A second outcome was the result of the action research projects conducted by each transdisciplinary cohort (see Table 3). A third outcome was the result of a survey designed to assess participants' attitudes and perceived competence with regard to meeting the needs of students at risk. A final outcome consisted of a series of focus group interviews. These 


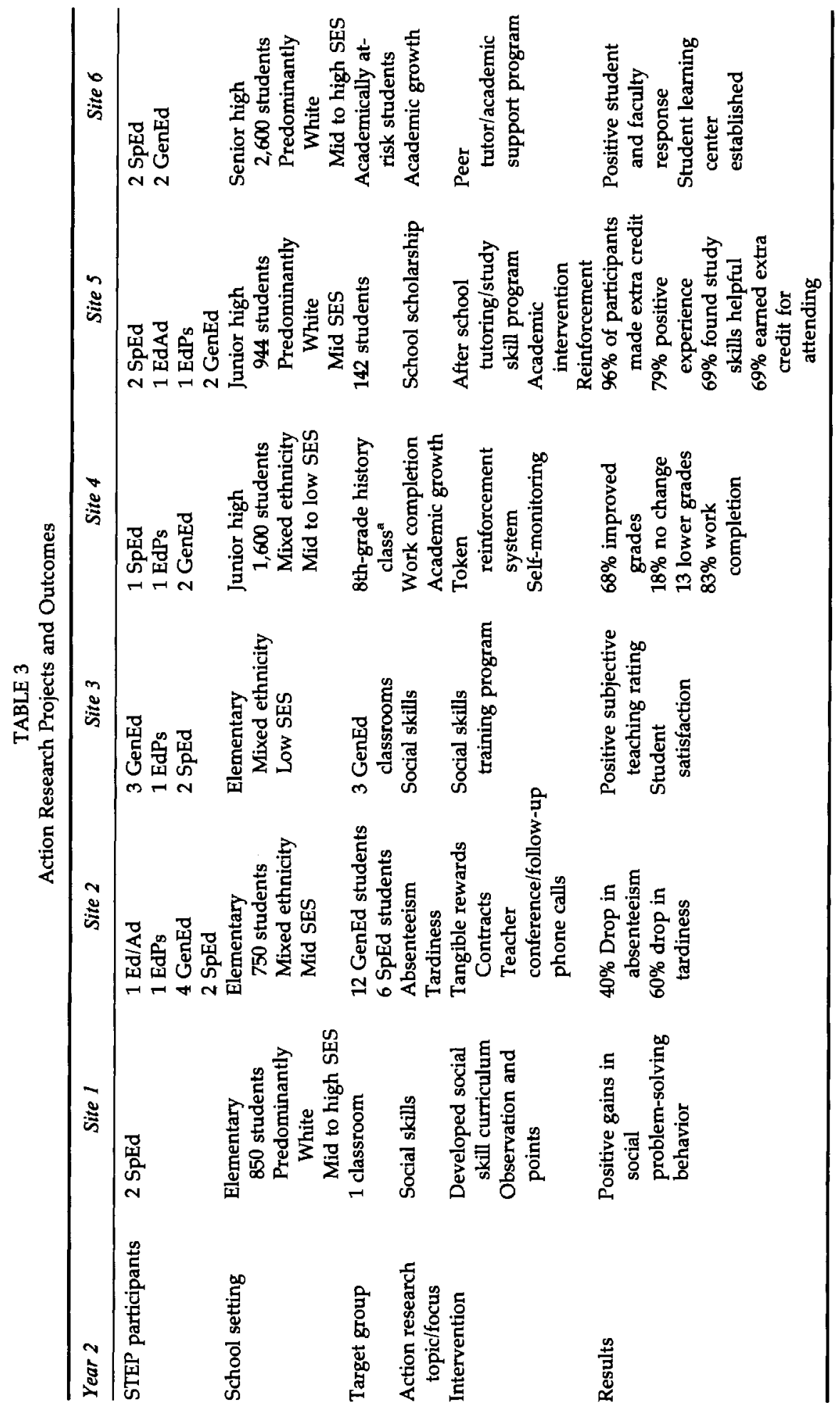




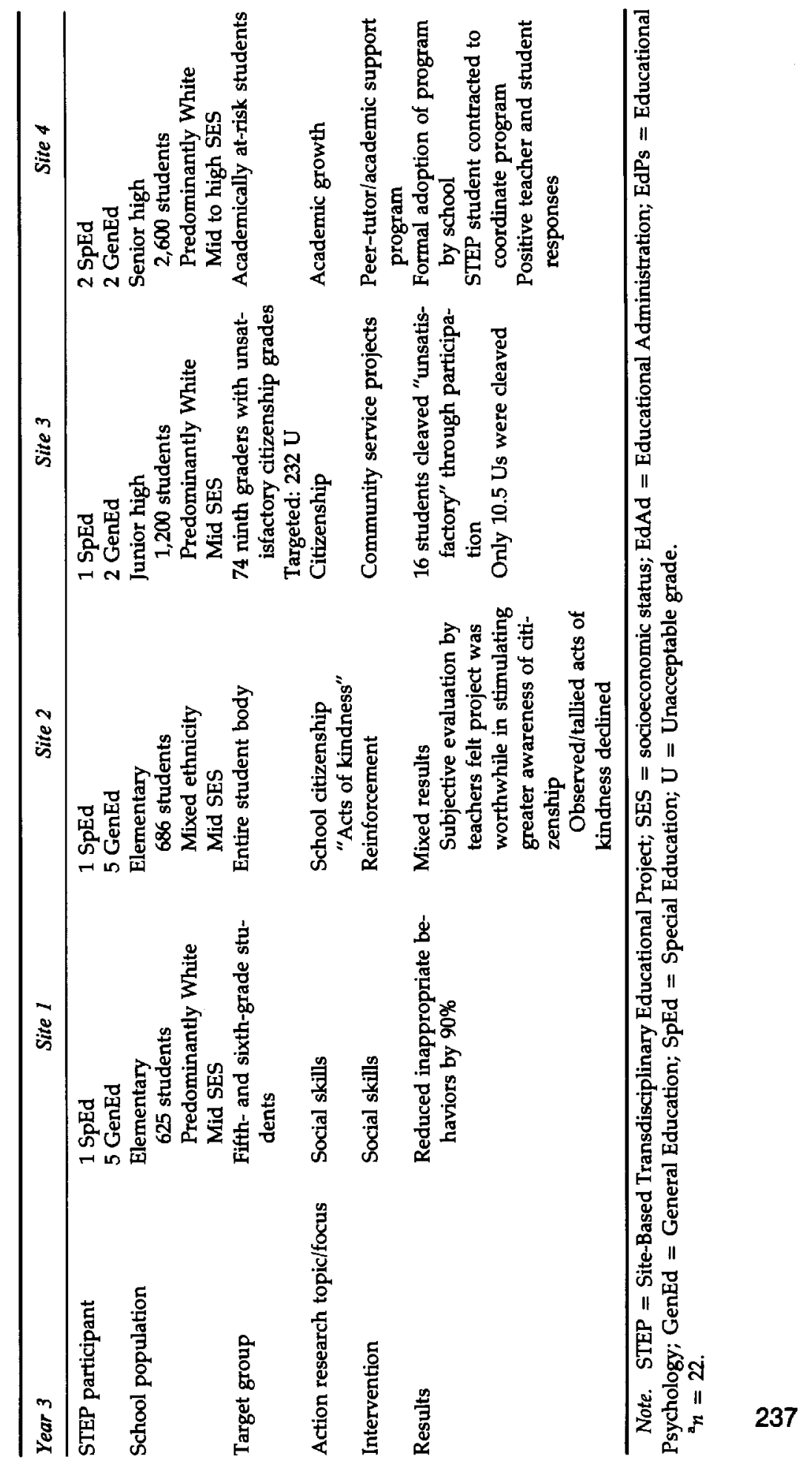


interviews were conducted to gather qualitative information from student participants and cooperating faculty from project sites regarding the overall experience.

\section{Action Research Results}

In general, most of the action research projects met some degree of success by reaching targeted objectives. Three projects were successful to the degree that the schools adopted the interventions after the completion of the STEP project. Specifically, one school adopted a peer-tutoring project for students at risk who were not eligible for special education services. Another school adopted two projects: an after-school study skills class and a school-work completion program.

There were some unanticipated, secondary outcomes from the action research projects. First, university students immediately learned the necessity of carefully developing objectives and methods of assessing the effects of their interventions. Most, if not all, learned this during coursework at the university. Despite "knowing" this fact for a course assignment or exam, many university students did not effectively apply this knowledge. As mentioned earlier, this was more apparent during the 1st year of the project. Therefore, some project objectives and outcomes were more defined than others that created vague contexts of operation. This in itself was a learning experience as university students discovered the importance of explicit goals and measurement procedures to document the effect of their intervention.

Second, university students quickly gained insight regarding pragmatic barriers to collaboration in the school. They realized that it is one thing to learn about the collaborative ethic and collaborative problemsolving process through the course of on-campus instruction, and quite another to experience it firsthand in authentic settings. Consequently, university students' initial predisposition to criticize schools that had limited evidence of collaboration was soon tempered by their own experience of coordinating schedules, roles, and responsibilities. In essence, prospective professionals soon discovered for themselves the harsh realities and challenges regarding collaboration in the school. These revelations reflect the value of action research as a vehicle for experiencing collaboration firsthand. A detailed example of one action research project is provided as follows to illustrate the overall nature and scope of the action research activities.

Case study. East Junior High School, comprised primarily of middleto upper-middle class students, had a citizenship policy that is standard throughout the district. Students, in addition to their academic grades, 
were rated on a citizenship scale of Honors $(\mathrm{H})$, Satisfactory (S), Not Satisfactory (NS), and Unacceptable (U). In recent years, the state legislature mandated that students not be allowed to graduate from their schools with U citizenship grades. Students can "work off" the U grades by performing alternative service or attending alternative programs. When a student has completed $8 \mathrm{hr}$ of alternative activities, one U grade is removed. The student group targeted by the STEP project participants at East Junior High was the body of students with excessive $U$ grades.

The transdisciplinary cohort included two teacher candidates from special education, four from educational studies (general education), one intern from educational administration, and one school psychology intern. This group developed a program called Strategies for Success, which provided an after-school study session 4 days per week. Team members met as a group during seminar sessions to discuss logistical coordination of developing and implementing their project. During these discussions, individual team members took on a task or assignment to be completed on their own before the next seminar sessions. At times, team members met at the school site to discuss the progress of the project, but this was not common given conflicting schedules. One day was devoted to learning specific learning strategies, another to tutoring in English, another to specific tutoring in history, and the final afternoon was for tutoring in math. The learning strategy instruction consisted of metacognitive learning strategies from the Strategies for Efficient Learning and Functioning curricula (see Welch, 1993, for a detailed description). On all occasions, general study help and tutoring was also available. For each hour of attendance at these study sessions, students were credited toward the time each needed to work off $U$ grades. In addition, some teachers offered extra credit or a free answer on a quiz if their students participated in the after-school study sessions. It was hoped that this type of incentive would encourage attendance by students desirous of academic support who did not necessarily have citizenship problems.

The study sessions were provided for a total of 33 days. Cohort team members coordinated the project and took turns supervising the afterschool sessions. There were 130 students who attended at least one session. Students attended for a total of $647 \mathrm{hr}$, resulting in a mean of $4.98 \mathrm{hr}$ and a range of 1 to $21 \mathrm{hr}$ per student. Approximately $97 \%$ of those students in attendance earned make-up credit for $U$ grades. Fourteen percent came one or more times just for study help, without earning credit for Us or any extra credit.

A student-satisfaction survey was administered to measure the desirability of the program. Seventy-six percent of the students agreed or strongly agreed that the extra help provided by the teachers was useful. 
Seventy-nine percent of the students appreciated having special subject area teachers available. Sixty-nine percent of the students found the general study skills instruction useful. Ninety percent of the students wanted general study help available daily, whereas $10 \%$ did not believe this was important. Even among students who verbally stated their desire to not attend, $86 \%$ admitted that without the after-school program, they would find it very difficult to make up their $U$ grades.

The impact of the project on the school as a whole was positive. The school received numerous telephone calls from parents who were appreciative of the opportunity for their children. Some members of the community also expressed interest in offering similar programs in their schools. Consequently, the program has been continued in the school even after the departure of the STEP project team.

\section{STEP Project Attitudinal and Perceived Competence Survey}

An investigation was conducted at the end of the project's 2nd year to determine the effects of special education coursework on the attitudes and perceived competencies of preservice general educators in working with students with disabilities in the mainstream classroom (Mayhew, 1994b). Three groups of teacher candidates were investigated. Group 1 included preservice elementary teachers enrolled in a course entitled "Educational Partnerships" (see Welch \& Sheridan, 1993, for course description). Group 2 comprised preservice general educators, counselors, school psychologists, and administrators participating in the STEP project. Group 3, a cohort of preservice secondary teachers who received no special education coursework, and did not participate in the STEP project, served as a comparison group.

A three-part questionnaire was used. Part 1 was designed to obtain demographic information about the participants. Part 2 was a 30-item, 6-point Likert-type attitude scale adapted from a previous study by Larrivee and Cook (1979). Part 3 was a 16-item, 6-point Likert-type survey of skills and knowledge about special education and mainstreaming adapted from a previous study by W. L. Phillips, Allred, Brulle, and Shank (1990).

Results of the investigation found that on the skills and knowledge survey, the group receiving special education instruction and the group participating in the STEP project had significantly higher mean scores than the comparison group, $F(2,55)=9.77, p<.001$. However, there was no significant difference on the attitude scale for the two groups receiving special education coursework. These findings suggest that although preservice general educators demonstrated positive attitudes 
toward mainstreamed students with disabilities, educators who received some special education instruction were more confident in their knowledge and ability to work with those students.

\section{STEP Project Focus Group Discussions}

The intent of the focus groups was to gather anecdotal information that could be used to assess participants' feelings and perceptions of their experiences. In essence, project coordinators wanted to know what (if anything) made the transdisciplinary educational partnership a meaningful experience for university students and practicing professionals. Similarly, which, if any, issues did participants identify?

A total of six focus groups consisting of three to five individuals from Year 3 met in a school room or university classroom after contract hours for a 60 -min interview session with a graduate research assistant who tape recorded the sessions. The recordings were then transcribed for analysis. University students and cooperating faculty at project sites from one elementary school and one junior high school were randomly selected from the pool of project sites to serve as focus group participants, as were the university students and cooperating faculty from the single participating senior high school. University students were interviewed separately from the cooperating project site faculty.

Each transcript was first independently read by the principal investigator, project director, and graduate research assistant to identify meaningful units of analysis (Miles \& Huberman, 1984). The readers convened as a group to share and discuss each of the meaningful units they had identified on their own to reach a consensus on interpretation. A total of 63 meaningful units were identified and then categorized independently. Approximately 1 week later, the group reconvened to discuss categories that each reader had independently generated. Using a comparative analysis procedure (Glasser \& Strauss, 1967), the group reached a consensus on eight common themes as shown in Table 4.

One identified category was transdisciplinary perspectives, which is characterized as pertaining to any information or perspective derived from other disciplines. Generally speaking, participating university students and cooperating professionals in project sites reported that the educational experience was enhanced when each program and discipline was represented. School climate was a second thematic category, which is characterized as the general attitude, morale, and atmosphere of the faculty and staff within a project site. The third category was communication, which was associated with any issue related to the verbal and written exchange of information. Respondents' comments were simply associated with the act of talking with others as a form of 
Transdisciplinary perspectives

School climate

Communication

Coordination

Pedagogical skill acquisition

Investment of effort

School impact

Collaboration
Preprofessionals reported gaining insights of other educational disciplines.

Positive: Preprofessionals reported that most cooperating supervisors were eager and willing to explore innovative methods to serve students at risk.

Negative: Faculty at one project site were isolated from colleagues, which resulted in minimized collaboration.

Faculty were resistant to "top-down" mandates for participating as cooperative supervisors of preprofessionals.

Preprofessionals indicated that informal discussion with peers and supervisors served an important function for technical and emotional support.

Formal timelines are necessary for completion of project activities.

Roles and responsibilities of cooperating site supervisors need to be written in a document.

Conflicting calendars of the university and public schools complicated coordination of project activities.

Cooperating site supervisors learned new skills and techniques from university students.

Preprofessionals reported that they assimilated skills from peers in other disciplines through interactions they would not have had if not involved in the STEP project.

Prospective special educators reported that they gained insight regarding the demands of general classroom settings through collaborative activities with their peers in general education and through observations/team teaching.

Faculty and staff of project sites must thoroughly understand the scope of project activities and their respective roles/responsibilities.

Workloads of cooperating site supervisors must be adapted and balanced to accommodate the role of supervising preprofessionals.

One STEP project graduate was contracted to coordinate the pilot project that was adopted and institutionalized by the school.

Three action research projects were adopted and institutionalized by the school after the STEP project was completed.

The principal of one project site reported that the entire school had reconceptualized the role of special education service delivery as a result of participating in the STEP project.

Preprofessionals reported that not seeing evidence of collaboration was equally enlightening as they gained an understanding of barriers.

Team teaching and project interactions were viewed as positive learning experiences

Relationships between the university and schools were generally enhanced. 
"networking." Another related category was coordination. Unlike the category of communication, coordination reflects the logistical management of the STEP project's operations. The fifth category was pedagogical skills, which included any comments regarding the assimilation of new methods of managing instruction and behavior. It was interesting to note that cooperating supervising teachers indicated they probably learned as much as the university students. Investment of effort was the sixth identified cluster. This category pertains to issues related to time and energy that had to be exerted in the development and implementation of transdisciplinary field experiences. The seventh category was school impact, which was conceptualized as any statement related to how the STEP project's activities effected the operation or organization of the school. The final category was collaboration, which was related to any respondents' comments regarding the process of working with other professionals either within the project site or with the university.

\section{Other STEP Project Outcomes}

In addition to meeting specific project objectives, the STEP project generated other, unexpected outcomes for students and faculty alike. A group of students and faculty made a presentation describing their STEP project experience at the conference of the American Psychological Association (Sheridan et al., 1993), and another group made a similar presentation at the Utah Federation of the Council of Exceptional Children (McFarland, Pierce, \& Zaharia, 1993). The graduate research assistant discussed the project at the national conference of the American Council on Rural Special Education (Mayhew, 1994a) and completed a masters thesis on the basis of his involvement (Mayhew, 1994b).

Despite the logistical, philosophical, and political differences among university faculty described earlier, many new professional and personal relationships have been forged as an outcome of the project. These relationships have resulted in greater collaboration for conducting research and an impetus for establishing interdisciplinary professional preparation programs as discussed in more detail as follows.

The discrepant levels of age and experience of the participating university students from various programs did not appear to be an issue. The results of the surveys and focus group interviews did not indicate the varying levels of student demographics made any noticeable difference. This may be due to the fact that the focus of the project's activities was on collaboration, which is essentially a new topical skill area and professional experience for all educators, regardless of discipline, age, and experience. The only apparent discrepancy was associ- 
ated with existing knowledge base of special education. Teacher candidates who did not have previous experience or coursework in special education appeared to be at a disadvantage with regard to terminology.

\section{DISCUSSION AND FUTURE DIRECTIONS}

It appears that the STEP project was effective in providing transdisciplinary field experiences to university students that increased their awareness of students at risk and of the need for working together to meet their needs. The outcomes of the STEP project have been generally positive and constructive, despite the operational challenges enumerated previously. Action research projects appear to have been effective vehicles for enhancing university students' inquiry and reflection process. University students and faculty learned more about colleagues from other disciplines and the process of collaborative problem solving. The experience also seems to have had a positive impact on students' perceived competency in teaching students with special needs. Finally, participants viewed the transdisciplinary project as a constructive and useful experience.

The intent of this article is to provide colleagues with ideas and insights that would enable similar programs to be implemented. Therefore, we have not attempted to sugarcoat the project's process or its outcomes as we feel it is imperative to share what worked and what did not within the context of suggestions for other institutions to consider. Collaboration, which was defined previously, served as the foundation for the preprofessionals' learning experience. However, the project coordinators also had much to learn about collaboration, especially with regard to the politics of collaboration.

\section{The Politics of Collaboration}

For political reasons, project coordinators wanted to include all of the local school districts. From an operational standpoint, it may have been advantageous to begin with one elementary and one secondary school setting in a single district. This approach would have minimized a number of logistical challenges. In retrospect, we discovered that we unknowingly breached Guskey's (1991) suggestions to think big and start small as well as to work as a team consisting of other program coordinators in the development of the project itself. Since the project's completion, Guskey's sage advice has been embellished with the operative adage, "think big, start small, and go slow" (Welch \& Sheridan, 1995, p. 166). 
A subtle yet significant difference in semantics was noted as potential project sites were identified. As the project progressed, it became clear that schools and districts were not receptive to the term site selection, as it connoted a one-way decision-making process on the part of the university. The term inferred that the university had somehow "anointed" a school as being "worthy" with little or no input from that constituency. It became evident that representatives from higher and public education had to mutually identify schools that met their respective agendas.

Similarly, we realized that identification and implementation of a new school site, rather than use of existing PDS schools, may have been more efficient by ultimately consolidating program field experiences. The project coordinators had anticipated, perhaps naively, that the implementation of a transdisciplinary field experience would be easier if incorporated within existing program structures, rather than if built from the ground up. In this way, no single program would have to change its current operation. It soon became apparent, however, that the conflicting structures and organization of respective programs did not synchronize efficiently. Consequently, a pilot project created entirely from scratch with no history, culture, or existing structures and procedures may have ultimately been more efficient. This reality became apparent once the STEP project coordinators realized that some university program directors were supportive of innovative programs and change as long as it "didn't mean doing things differently." However, such an approach and attitude essentially maintains the status quo and does little to bring about new professional preparation programs if the intent and perception of a pilot project is to temporarily exist outside the realm of current programs until its operation expires. Consequently, there is the potential danger of a mentality associated with "pilot projects" whereby participants assume that programs will merely return to the way they were after the temporary experimental condition has terminated.

A smaller scale, pilot project may have allowed this type of program to go outside the traditional calendar of the university's academic calendar to coincide with the school calendar. Participating university students would need to be recruited in the spring of the preceding year and to be informed that they would begin their field experiences at the same time the public school year began. The challenge of coordinating university faculty's schedule, however, remains. Would university program coordinators be willing to begin their activities earlier? This issue cannot be easily resolved as long as the university and public school calendars remain different.

Equally disquieting were the unexpected philosophical and "turf" 
issues that surfaced. Project coordinators erroneously assumed that professionals in preparation programs across the Graduate School of Education embraced the current rhetoric of collaboration in meeting the needs of children and youth at risk. A number of incidents indicated otherwise. First, some program facilitators were quite blatant in their lack of support of the project and questioned the need for preparing prospective teachers for collaboratively working with other educators. The focus group interviews with teacher candidates from general education also revealed that some faculty in the elementary and secondary teacher education programs actually attempted to dissuade students from voluntarily participating in the program. Second, some faculty members expressed a concern that their autonomy, academic freedom, and program's integrity would somehow be compromised by the project. Such concerns may have been avoided if these individuals had been included in the initial phases of conceptualization and development. These concerns appear to have subsided to some extent over the course of the 3-year project. Third, initially, some clinical faculty did not want to share their school sites for fear that the school and its staff would be inundated by university students. This concern did come to fruition to some extent. Faculty and staff at one school felt overwhelmed with additional responsibilities yet eventually peripherally participated. However, the same clinical faculty in the teacher education program did not want to create or visit any other sites and therefore acquiesced in allowing STEP project participants access to existing PDS. In fairness to the faculty in the program who were less supportive, it is worth noting that their program had recently undergone comprehensive restructuring. Consequently, their reluctance and lack of support may have been due to "programmatic fatigue" that had resulted from years of seemingly endless faculty meetings.

Based on what has been learned throughout the STEP project, the Graduate School of Education at the University of Utah is currently developing a pilot project at the master's level, which will consist of a common core of knowledge for all students in each professional preparation program. A task force comprises program and faculty representatives from each department. The task force charged with conceptualizing this program chose to implement this project at the master's level based on what was learned from the STEP project. All of the departmental programs had more flexibility within their master's programs as students could take various courses from other departments as allied hours. Furthermore, internships from each program bore greater structural resemblance with each other and, therefore, appeared easier to coordinate. A component of the common core is collaboration. A case study approach with guided field experiences will be incorporated in the 
program. The common core will not consist of isolated and segmented courses for each topical area. Instead, thematic blocks of time will be allocated over academic quarters to explore and apply various topics, such as collaboration, through case studies and discussion of field experiences. The task force creating this program is working diligently with representatives from each school district to identify potential field sites. This joint effort is considering many of the insights and recommendations that came from the "first STEP" of creating transdisciplinary professional preparation programs.

\section{REFERENCES}

Amedore, G. H., \& Knoff, H. M. (1993). Boundary spanning activities and the multidisciplinary team process: Characteristics affecting school psychological consultation. Joumal of Educational and Psychological Consultation, 4, 343-356.

Blaine, R., \& Sobsy, R. (1983). Implementing transdisciplinary services for severely handicapped persons. Special Education in Canada, 58, 12-14.

Clift, R., Veal, M. L., Johnson, M., \& Holland, P. (1990). Restructuring teacher education through collaborative action research. Joumal of Teacher Education, 41(2), 52-62.

Downhower, S. L., Melvin, M. P., \& Sizemore, P. (1990). Improving writing instruction through teacher action research. Joumal of Staff Development, 11(3), 22-27.

Glasser, B. G., \& Strauss, A. L. (1967). The discovery of grounded theory: Strategies for qualitative research. New York: Alpine.

Golightly, C. J. (1987). Transdisciplinary training: A step forward in special education teacher preparation. Teacher Education and Special Education, 10(3), 126-130.

Goodlad, J. I., \& Field, S. (1993). Teachers for renewing schools. In J. I. Goodlad \& T. C. Lovitt (Eds.), Integrating general and special education (pp. 229-252). Columbus, $\mathrm{OH}$ : Merrill.

Gove, M. K., \& Kennedy-Calloway, C. (1992). Action research: Empowering teachers to work with at-risk students. Joumal of Reading, 35, 526-534.

Guskey, T. R. (1991). Enhancing the effectiveness of professional development programs. Joumal of Educational and Psychological Consultation, 2, 239-247.

Kaufman, J. M., \& Hallahan, D. P. (1993). Toward a comprehensive delivery system for special education. In J. I. Goodlad \& T. C. Lovitt (Eds.), Integrating general and special education (pp. 73-102). Columbus, $\mathrm{OH}$ : Merrill.

Kosmidou, C., \& Usher, R. (1991). Facilitation in action research. Interchange, 22(4), 24-40.

Kyle, D. W., \& Hovda, R. A. (1987). Action research: Comments on current trends and future possibilities. Peabody Joumal of Education, 64, 170-175.

Larrivee, B., \& Cook, L. (1979). Mainstreaming study of the variables affecting teacher attitude. Journal of Special Education, 13, 315-324.

Liston, D. P., \& Ziechner $x$ K. M. (1990). Reflective teaching and action research in preservice teacher education. Jourmal of Education for Teaching, 16, 235-254.

Maher, C. A., \& Bennett, R. E. (1984). Planning and evaluating special education services. Englewood Cliffs, NJ: Prentice-Hall.

Mayhew, J. C. (1994a, March). Are preseroice general educators being adequately prepared for inclusion? Paper presented at the national conference of the American Council on Rural Special Education, Austin, TX. 
Mayhew, J. C. (1994b). Effects of special education coursework on attitudes and perceioed competencies of preservice general educators towards students with disabilities. Unpublished master's thesis, University of Utah, Salt Lake City.

McFarland, J., Pierce, S., \& Zaharia, C. (1993, September). Reduction of absenteeism and tardiness in an urban elementary school. Paper presented at the conference of the Utah Federation of the Council for Exceptional Children Conference, Park City, UT.

Miles, M. B., \& Huberman, A. M. (1984). Qualitative data analysis: A sourcebook of new methods. Beverly Hills, CA: Sage.

Oja, S. N., \& Pine, G. J. (1987). Collaborative action research: Teachers' stages of development and school contexts. Peabody Joumal of Education, 64, 96-115.

Phillips, V., \& McCullough, L. (1990). Consultation-based programming: Instituting the collaborative ethic in schools. Exceptional Children, 56, 291-304.

Phillips, W. L., Allred, K., Brulle, A. R., \& Shank, K. S. (1990). The regular education initiative: The will and skill of regular educators. Teacher Education and Special Education, 13, 182-186.

Pugach, M., \& Allen-Meares, P. (1985). Collaboration at the preservice level: Instructional and evaluation activities. Teacher Education and Special Education, 8, 3-11.

Ross, D. D. (1987). Action research for preservice teachers: A description of why and how. Peabody Joumal of Education, 64, 131-150.

Sheridan, S. M., Welch, M., Colton, D., Wilson, B., Ashcraft, C., Hoerner, A., \& Mower, M. (1993, August). Sile-based transdisciplinary educational partnerships: Implementing the collaborative ethic in schools. Paper presented at the meeting of the American Psychological Association, Toronto, Canada.

Sindelar, P., Pugach, M., Griffin, C., \& Seidl, B. (1995). Reforming teacher education: Challenging the philosophy and practices of educating regular and special educators. In J. L. Paul, H. Rosselli, \& D. Evans (Eds.), Integrating school restructuring and special education reform (pp, 140-166). Fort Worth, TX: Harcourt Brace.

Strawderman, C., \& Lindsey, P. (1995). Keeping up with the times: Reform in teacher education. Journal of Teacher Education, 46(2), 95-100.

Villa, R., \& Thousand, J. (1988). Enhancing success in heterogeneous classroom and schools: The power of partnerships. Teacher Education and Special Education, 11, 144-154.

Wallace, M. (1987). A historical review of action research. Joumal of Education for Teaching, 13, 97-115.

Welch, M. (1993). Establishing educational partnerships with strategic interventions through video-mediated staff development. Joumal of Educational and Psychological Consultation, 4, 267-273.

Welch, M., \& Sheridan, S. M. (1993). Educational partnerships in teacher education: Reconceptualizing how teacher candidates are prepared for teaching students with disabilities. Action in Teacher Education, 15(3), 35-46.

Welch, M., \& Sheridan, S. M. (1995), Educational partnerships: Serving students at risk. Ft. Worth, TX: Harcourt Brace.

Marshall Welch, PhD, is an associate professor in the Department of Special Education at the University of Utah. His research interest is in the area of interdisciplinary collaboration for serving students with special needs.

Susan M. Sheridan, $\mathrm{PhD}$, is an associate professor in the Department of Educational Psychology at the University of Utah. Her research interests are in the areas of behavioral consultation and home-school partnerships. 
Brett Wilson and Denise Colton are doctoral candidates in the Department of Educational Psychology at the University of Utah. Both are interested in the role of school psychologists in collaborative consultation.

John C. Mayhew is a doctoral candidate in the Department of Special Education and is pursuing his studies in the area of distance education.

Action Editor: Joseph E. Zins 